\title{
Optimizing Basement Construction Methods
}

\author{
Bao- Nguyen Huu ${ }^{1}$ \\ ${ }^{1}$ Department of Technology, Dong Nai Technology University, Bien Hoa, Vietnam
}

\begin{tabular}{|c|c|}
\hline Article Info & ABSTRACT \\
\hline Article history: & \multirow{6}{*}{$\begin{array}{l}\text { The underground part of SSG TOWER includes } 4 \text { basements, } 4 \text { basements at } \\
\text { a height of }-13.2 \mathrm{~m} \text {. Combined with the construction of } 3 \mathrm{~m} \text { deep foundation, } \\
\text { therefore, the minimum excavation depth is required to }-16.2 \mathrm{~m} \text {. Due to the } \\
\text { construction work in residential area, relatively ground, with large excavation } \\
\text { depth and geology of the interaction area (clay layer up to } 30 \mathrm{~m} \text { ), the options } \\
\text { for using diaphragm wall with drilled piles Small area, Laser piles or solier } \\
\text { piles to make retaining walls during construction do not have that feature, so } \\
\text { the author chooses the option of using reinforced concrete barrette walls for } \\
\text { retaining walls during construction and as tunnel walls for this project. }\end{array}$} \\
\hline Received Oct 12, 2021 & \\
\hline Revised Dec 10, 2021 & \\
\hline Accepted Dec 25, 2021 & \\
\hline Keywords: & \\
\hline $\begin{array}{l}\text { Divide and Conquer } \\
\text { Optimizing }\end{array}$ & \\
\hline
\end{tabular}

Top-Down Method

\begin{abstract}
The semi-topdown construction method was chosen to ensure safety during construction because the excavation depth of the work is quite large and the geology of this area is quite weak. This measure completely solves the strut system because using the floor structure of the building to support this system has high stability. Limiting the influence of settlement, cracking, and slippage to neighboring works a lot. Fast construction but in return for high technical requirements, high construction costs. Choose diaphragm wall thickness of $1.0 \mathrm{~m}$, base depth of $46.6 \mathrm{~m}$ including standard barrete panels.

The author uses 2D Plaxis simulation to calculate ground stability, stress and displacement, moment, and shear force generated in diaphragm wall during basement construction. The author analyzes using the optimization algorithm to compare and find the suitable solution.
\end{abstract}

This is an open access article under the CC BY-SA license.

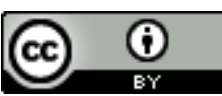

\section{INTRODUCTION}

The land area has a total construction area of 5,983.2 m2 located at Dien Bien Phu street, Ward 25, Binh Thanh District. The land has a very convenient location for traffic, meeting demand for landscape architecture, usability for a supermarket, commercial project commercial, services, offices and apartments, especially the project has a role in contributing to the creation of landscape for the area.

The project construction site has a flat topography and is relatively low compared to the size of the project. The approved leveling plan of Binh Thanh district is $>2 \mathrm{~m}$, the national average elevation $+1.0 \mathrm{~m}$.

The Southwest is adjacent to Dien Bien Phu Street. The Northwest is adjacent to D1 road. The Southeast adjoins alley 30/4. The Northeast is adjacent to alley 114 


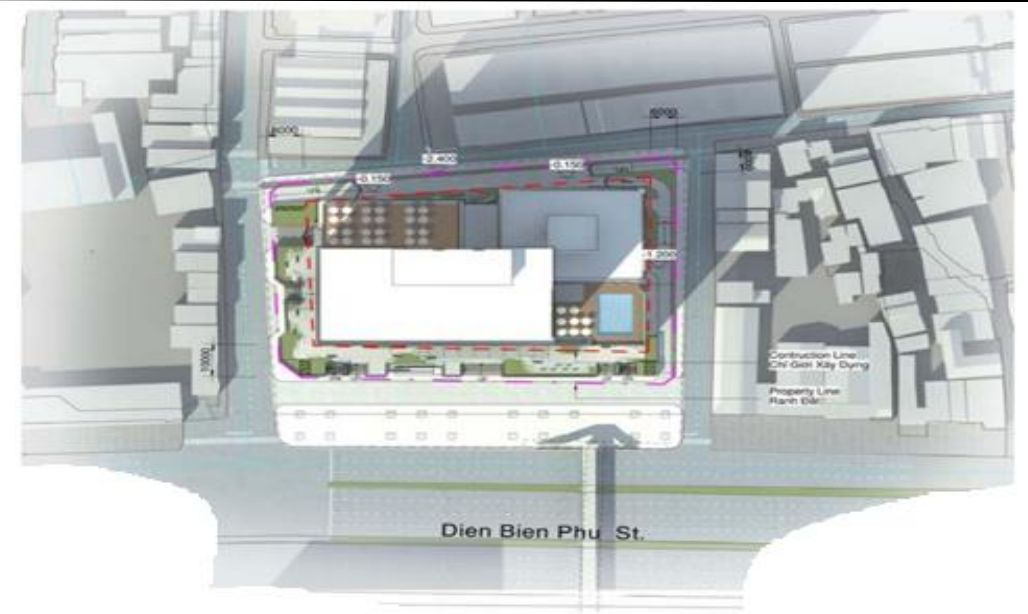

Figure 1. Overall Project Plan

\section{RESEARCH METHOD}

\subsection{Optimal Theory}

- $\quad$ sumWisumWi is the sum of wjwjs with $i \leq j i \leq j$.

- $\quad$ sumDisumDi is the sum of the djdjs with $i \leq j i \leq j$

- $\quad$ sumWSisumWSi is the sum of $w j * \operatorname{sumDjwj} * \operatorname{sumDj}$ with $i \leq j i \leq j$.

Then $\operatorname{cost}(L, R) \operatorname{cost}(L, R)$ is the construction phase 1 technique with the index in the interval $[L, R][L, R]$ to the stage 2 excavation position.

in RR is: sumWSL-sumWSR-sumDR $*($ sumWL-sumWR)sumWSL-sumWSR-sumDR $*$ (sumWL-sumWR). Thus we can construct the function eval(i,j)eval $(\mathrm{i}, \mathrm{j})=$ technique of stage 1 and stage 2 at $\mathrm{i}$ and $\mathrm{j}=$ $\operatorname{cost}(1, \mathrm{i})+\operatorname{cost}(\mathrm{i}+1, \mathrm{j})+\cos t(\mathrm{j}+1, \mathrm{n}+1) \cos t(1, \mathrm{i})+\cos t(\mathrm{i}+1, \mathrm{j})+\cos t(\mathrm{j}+1, \mathrm{n}+1)$.

Then $\operatorname{cost}(L, R) \operatorname{cost}(L, R)$ is the construction phase 3 technique whose index in the $[L, R][L, R]$ segment to the 4thexcavationpositioninRRis:sumWSL-sumWSR-sumDR*(sumWL-sumWR)sumWSL-sumWSR-sumDR $*($ sumWL-sumWR). Thus, we can construct the function eval(i,j)eval(i,j) = stage 3 and stage 4 techniques at $i$ and $j=\operatorname{cost}(1, i)+\operatorname{cost}(i+1, j)+\operatorname{cost}(j+1, n+1) \operatorname{cost}(1, i)+\operatorname{cost}(i+1, j)+\operatorname{cost}(j+1, n+1)$.

However, the solution $\mathrm{O}(\mathrm{N} 2) \mathrm{O}(\mathrm{N} 2)$ is not good enough to fully solve this problem.

Let best(i)best(i) be the best $\mathrm{j}>\mathrm{ij}>\mathrm{i}$ position if we have placed a stage at $\mathrm{i}$. So the result of the problem will be $\min ($ eval(i,besti)min(eval(i,besti) with $1 \leq \mathrm{i}<\mathrm{n} 1 \leq \mathrm{i}<\mathrm{n}$.

Comment:

- besti $\leq$ besti+1 besti $\leq$ besti+1. Can explicitly write the formula to prove.

- We can compute the bestibesti in any order. Since the bestbest values are not related, for example we can calculate best(3)best(3) then best(1)best(1) and best(2)best(2).

Thus, we have an algorithm that uses the divide-and-conquer idea as follows:

The solve( $L, R$, from,to)solve(L,R,from,to) function computes the best(L..R)best(L..R), knowing that they are in the [from.. to][from..to].

\subsection{ROJECT DESCRIPTION}

The proposed option here is the construction of Semi-Topdowm

The actual construction of SSG Tower has 2 basements, but the elevation cote of basement B2 is at natural ground level. In this study, the author lowered the elevation cote of B2 basement to $-7.8 \mathrm{mSL}$ (SL: structural 
elevation cote, GL: elevation cote above the natural ground; $-7.8 \mathrm{mSL}$ corresponds to $-7.8 \mathrm{mGL}$ ). In addition, the construction of the foundation tower is $3 \mathrm{~m}$ high, so the minimum excavation depth is $-10.9 \mathrm{mGL}$ (including the $100 \mathrm{~mm}$ thick concrete lining).

Semi-Topdown construction method was selected to ensure safety during construction because the excavation depth of the work is quite large and the geology of this area is quite weak. This measure completely solves the strut system because using the floor structure of the building to support this system has high stability. Limit the influence of settlement, cracking, sliding to neighboring works. Fast construction but in return for high technical requirements, high construction costs.

Choose diaphragm wall thickness $1.0 \mathrm{~m}$, base depth $46.6 \mathrm{~m}$ including standard barrete panels $2.8 \times 1.0 \mathrm{~m} 2$. The author uses Plaxis 2D software to calculate ground stability; displacement, moment, and shear force generated in diaphragm wall during basement construction.

\section{Implementation content}

- Layout of construction site and kingpost

- Set construction sequence

- Check the displacement and calculate the earth retaining wall through the Plaxis . model

- Calculate kingpost and link between kingpost and girder system during construction

- Use the optimization algorithm (divide and conquer) to choose the best solution for the construction stages

\subsection{CONSTRUCTION SEQUENCE}

The construction method given is based on many other factors but must ensure the technical requirements for the bearing capacity of the diaphragm wall, displacement of the diaphragm wall, and the bearing capacity of the kingpost. In addition, it must meet the requirements of schedule and save costs as low as possible. Based on the requirements and construction conditions of the project, students give the construction sequence a shown below.

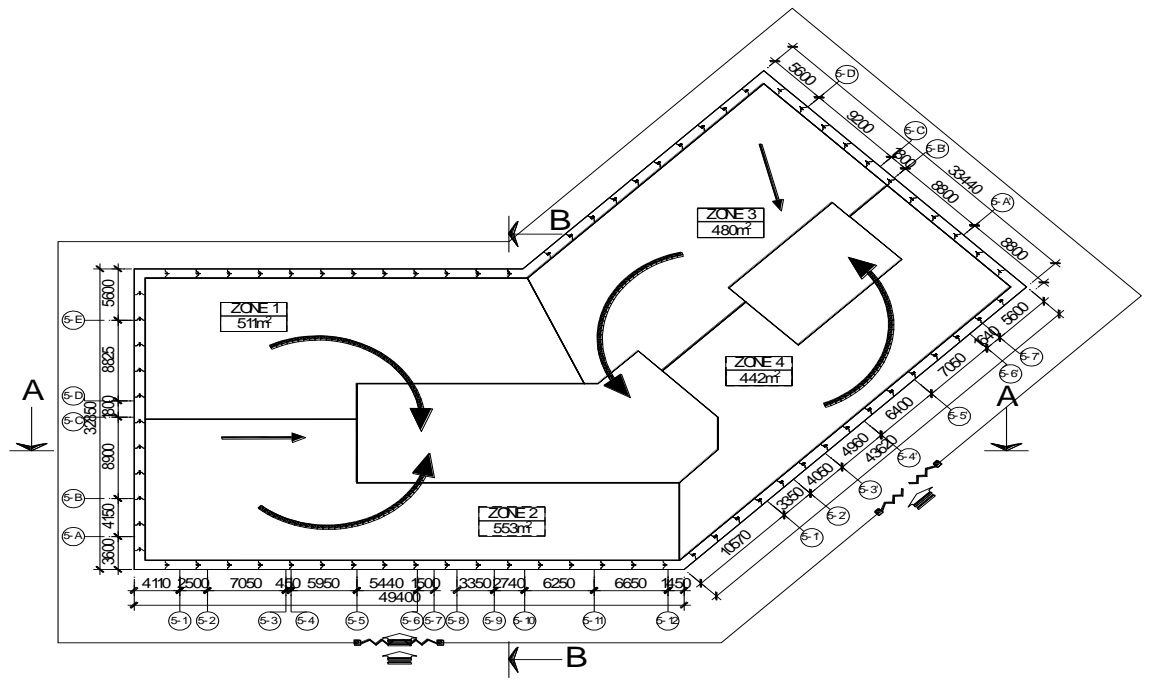

Figure 2. Plan of division of construction zone and excavation direction of the 1st floor

Sequence of basement construction:

Step 1:

- Dig the first phase from the natural ground level to the height of $-2,200 \mathrm{mGL}$

Step 2:

- Set up the phase and construction of reinforced concrete floor 1

Step 3: 
- Cancel the first floor and dig the second phase from -2,200mGL to -4,550mGL

Step 4:

- Construction of concrete, reinforced concrete basement floor B1

Step 5:

- Dig the 3rd phase from the height of -4,550mGL to -8,400mGL and localize the bottom (the deepest pit is $-10.9 \mathrm{mGL}$ )

Step 6:

- Construction of lining concrete, reinforced concrete for basement floor B2 and foundation

\subsection{CALCULATION PROCESS}

- $\quad$ All kingposts will be tested for bearing capacity according to the order of earthwork construction

- Determine the overall construction sequence of the basement, the construction steps of earthwork, the location of the kingpost

- $\quad$ Build an ETABS model corresponding to each actual construction phase established

- Determination of construction loads acting on the floor and load combinations

- Calculating the internal force of kingpost in each construction phase

- Determine the calculated length of the kingpost in each construction phase and conduct the calculation to check the bearing capacity of the kingpost corresponding to each stage.

Table.1 Sectional characteristics of Kingpost

\begin{tabular}{|c|c|c|c|c|c|c|c|c|c|c|}
\hline \multirow{2}{*}{ Number } & \multirow{2}{*}{ Symbol } & $\mathrm{H}$ & $\mathrm{B}$ & $\mathrm{t}_{\mathrm{w}}$ & $\mathrm{t}_{\mathrm{f}}$ & $\mathrm{A}$ & $\mathrm{J}_{\mathrm{x}}$ & $\mathrm{J}_{\mathrm{y}}$ & $\mathrm{W}_{\mathrm{x}}$ & $\mathrm{W}_{\mathrm{y}}$ \\
\cline { 3 - 12 } & & $\mathrm{mm}$ & $\mathrm{mm}$ & $\mathrm{mm}$ & $\mathrm{mm}$ & $\mathrm{cm}^{2}$ & $\mathrm{~cm}^{4}$ & $\mathrm{~cm}^{4}$ & $\mathrm{~cm}^{3}$ & $\mathrm{~cm}^{3}$ \\
\hline 1 & $\mathrm{KP} 1$ & 350 & 350 & 12 & 19 & 170 & 39506.2 & 13582 & 2257.5 & 776.09 \\
\hline 2 & $\mathrm{KP} 2$ & 400 & 400 & 13 & 21 & 215 & 65361.6 & 22407 & 3268.1 & 1120.3 \\
\hline 3 & KP3 & 350 & 350 & 12 & 19 & 170 & 39506.2 & 13582 & 2257.5 & 776.09 \\
\hline
\end{tabular}

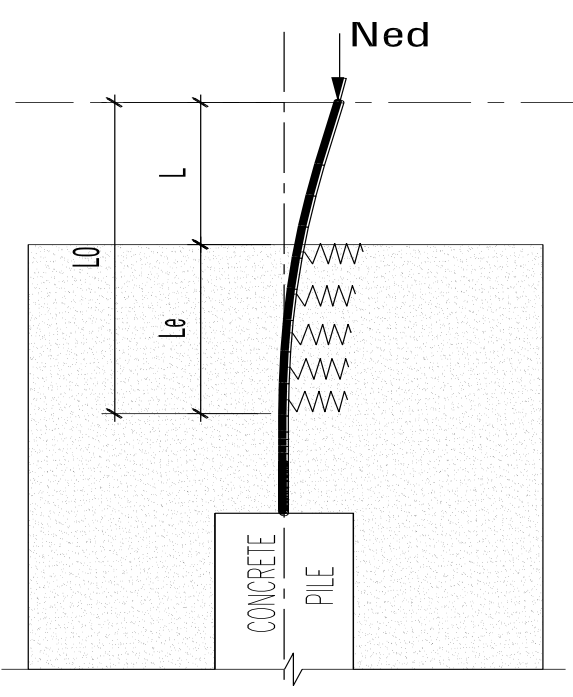

Figure.2 Diagram of determining the mounting length in the ground of kingpost

L: the length of the pile from the bottom of the platform to the leveling level below

$\alpha_{\varepsilon}$ : The coefficient of deformation is determined according to the following formula:

$$
\alpha_{\varepsilon}=\sqrt[5]{\frac{k b_{p}}{\gamma_{c} E I}}
$$




\subsection{SPECIFIC CALCULATION}

Because after construction of bored pile and kingpost, the borehole is filled with sand at the construction site (sand and dust), so we have: $\mathrm{k}=7000 \mathrm{kN} / \mathrm{m}^{4}$.

Table.2 Geometric parameters of kingpost

\begin{tabular}{|c|c|c|c|c|c|c|c|c|}
\hline \multirow{2}{*}{ Kingpost } & $\mathrm{k}$ & $\mathrm{d}$ & $\mathrm{b}_{\mathrm{p}}$ & & $\mathrm{I}$ & $\mathrm{E}$ & $\alpha_{\mathrm{e}}$ & $l_{\varepsilon}$ \\
\cline { 2 - 6 } \cline { 7 - 10 } & $\mathrm{kN} / \mathrm{m}^{4}$ & $\mathrm{~m}$ & $\mathrm{~m}$ & & $\mathrm{~cm}^{4}$ & $\mathrm{kPa}$ & $1 / \mathrm{m}$ & $\mathrm{m}$ \\
\hline $\mathrm{KP} 1$ & 7000 & 0.35 & 1.03 & 3 & 39506 & 210000000 & 0.492 & 4.07 \\
\hline $\mathrm{KP} 2$ & 7000 & 0.4 & 1.1 & 3 & 65362 & 210000000 & 0.451 & 4.43 \\
\hline $\mathrm{KP} 3$ & 7000 & 0.35 & 1.03 & 3 & 39506 & 210000000 & 0.492 & 4.07 \\
\hline
\end{tabular}

Table.3 Determining the calculated length of kingpost

\begin{tabular}{|c|c|c|c|c|c|c|c|c|}
\hline \multirow{2}{*}{ Phase } & \multirow[t]{2}{*}{ Floor } & \multicolumn{2}{|c|}{$\begin{array}{l}\text { Load } \\
\text { outside } \\
(\mathrm{kN} / \mathrm{m})\end{array}$} & \multirow[t]{2}{*}{ Kingpost } & \multirow{2}{*}{$\begin{array}{l}\mathrm{L} \\
\mathrm{m}\end{array}$} & \multirow{2}{*}{$\begin{array}{l}l_{e} \\
\mathrm{~m}\end{array}$} & \multirow{2}{*}{$\begin{array}{c}\mathrm{L} \\
\text { total } \\
\mathrm{m}\end{array}$} & \multirow{2}{*}{$\begin{array}{c}\mathrm{L}_{\text {count }} \\
\mathrm{m}\end{array}$} \\
\hline & & MC A-A & MC B-B & & & & & \\
\hline \multirow{3}{*}{1} & \multirow{3}{*}{1} & \multirow{3}{*}{-87.9} & \multirow{3}{*}{-145.1} & KP1 & 4.55 & 4.43 & 8.98 & 7.19 \\
\hline & & & & KP2 & 4.55 & 4.43 & 8.98 & 7.19 \\
\hline & & & & KP3 & 4.55 & 4.43 & 8.98 & 7.19 \\
\hline \multirow{6}{*}{2} & \multirow{3}{*}{1} & \multirow{3}{*}{294.3} & \multirow{3}{*}{245.5} & KP1 & 4.2 & 0.00 & 4.20 & 2.94 \\
\hline & & & & KP2 & 4.2 & 0.00 & 4.20 & 2.94 \\
\hline & & & & KP3 & 4.2 & 0.00 & 4.20 & 2.94 \\
\hline & \multirow{3}{*}{ Basement B1 } & \multirow{3}{*}{-978.7} & \multirow{3}{*}{-992.1} & KP1 & 6.6 & 0.00 & 6.60 & 5.28 \\
\hline & & & & KP2 & 6.6 & 0.00 & 6.60 & 5.28 \\
\hline & & & & KP3 & 6.6 & 0.00 & 6.60 & 5.28 \\
\hline
\end{tabular}

\section{Note:}

- In the calculation table on the calculated length coefficient $\mu$ of kingpost in the 1st period, take $\mu=$ 0.8 . In the second stage: for the first floor, $\mu=0.7$, for the basement floor B1 $\mu=0.8$

- The external load in the table above is the compression (pull) force acting on the basement floor during construction, determined in Plaxis software.

\section{RESULTS AND DISCUSSION}

Phase 1 


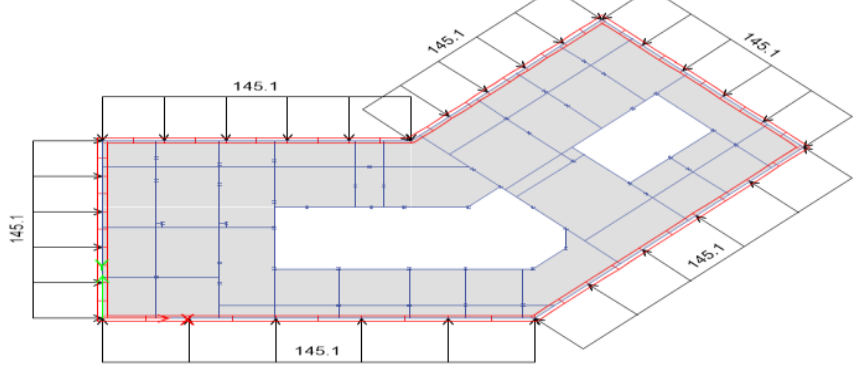

Figure.3 Ground pressure plane acting on the 1st floor in phase 1

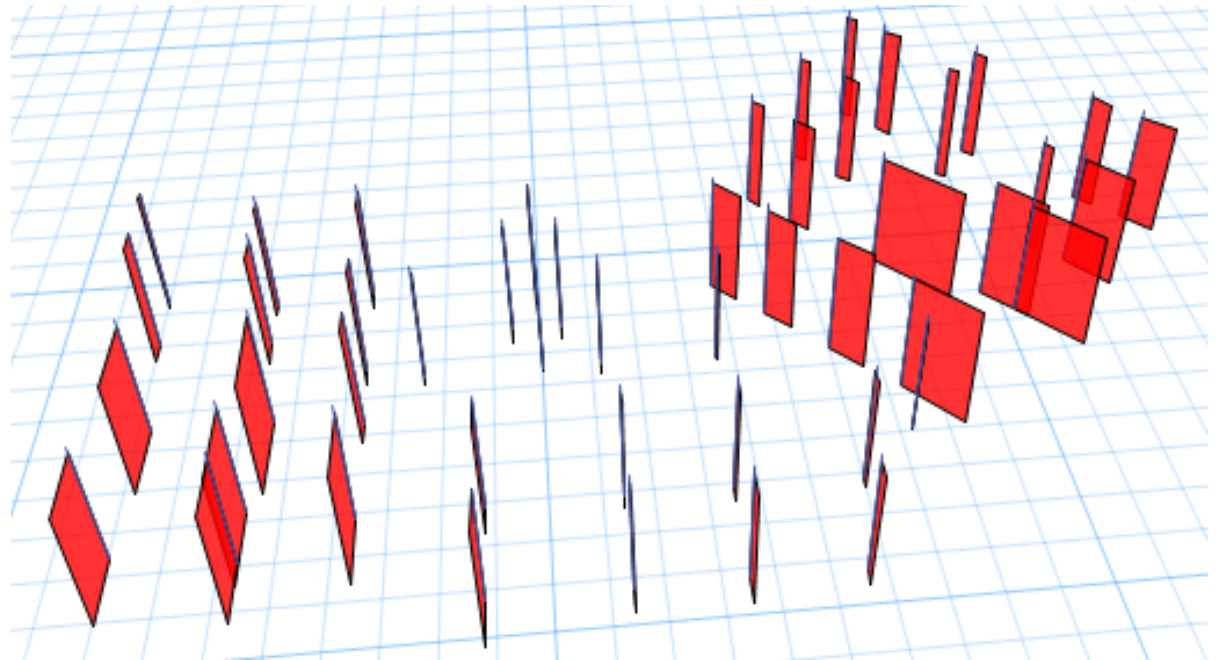

$\operatorname{Max}=-31.098 \mathrm{kN}$ at $[51.8517 \mathrm{~m}, 12.3115 \mathrm{~m}, 0 \mathrm{~m}] ;$ Min $=-1501.2762 \mathrm{kN}$ at $[52.6831 \mathrm{~m}, 27.6413 \mathrm{~m}, 0 \mathrm{~m}]$

Fig.4 Longitudinal force of kingpost system in period 1

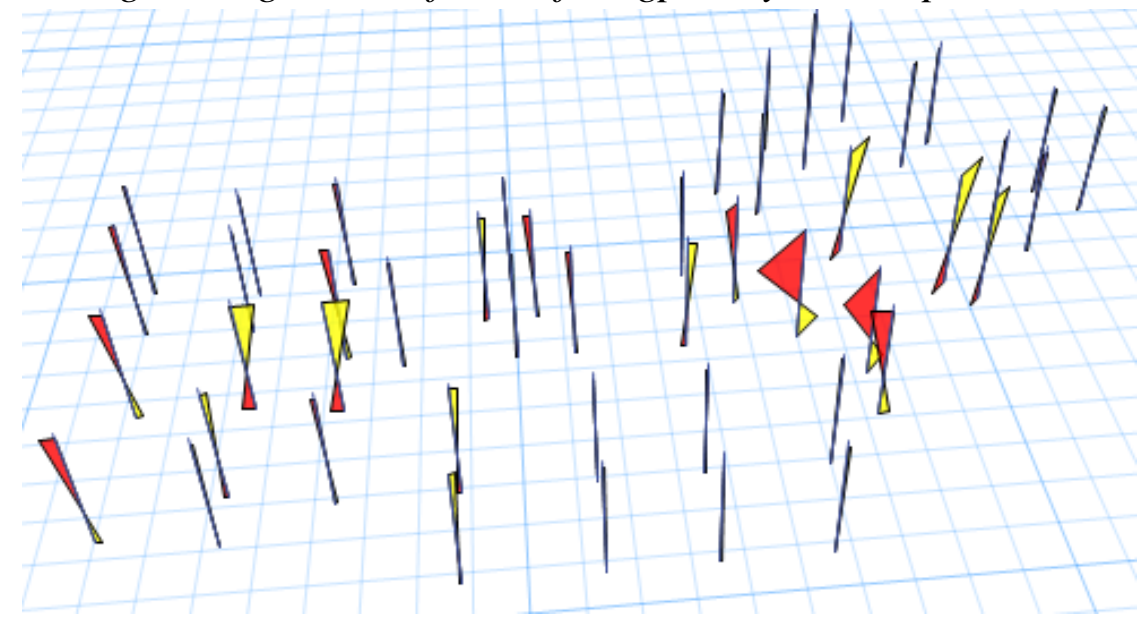


$\operatorname{Max}=66.5903 \mathrm{kN}-\mathrm{m}$ at $[58.9522 \mathrm{~m}, 23.7082 \mathrm{~m}, 0 \mathrm{~m}] ;:$ in $=-125.8434 \mathrm{kN}-\mathrm{m}$ at $[48.1324 \mathrm{~m}, 19.5041 \mathrm{~m}, 0 \mathrm{~m}]$

Fig.5 Moment M22 of kingpost system in phase 1

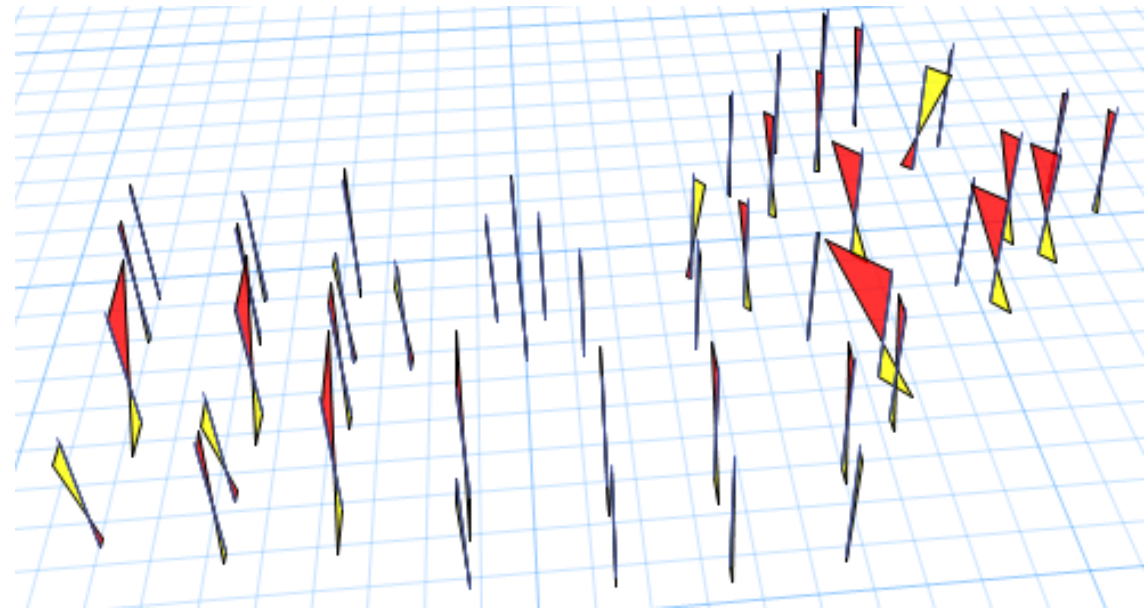

$\operatorname{Max}=67.5637 \mathrm{kN}-\mathrm{m}$ at $[19.2576 \mathrm{~m}, 8.675 \mathrm{~m}, 0 \mathrm{~m}] ;:$ in $=-111.7043 \mathrm{kN}-\mathrm{m}$ at $[19.2576 \mathrm{~m}, 8.675 \mathrm{~m}, 0 \mathrm{~m}]$

Fig.6 Moment M33 of kingpost system in phase 1

Phase 2 


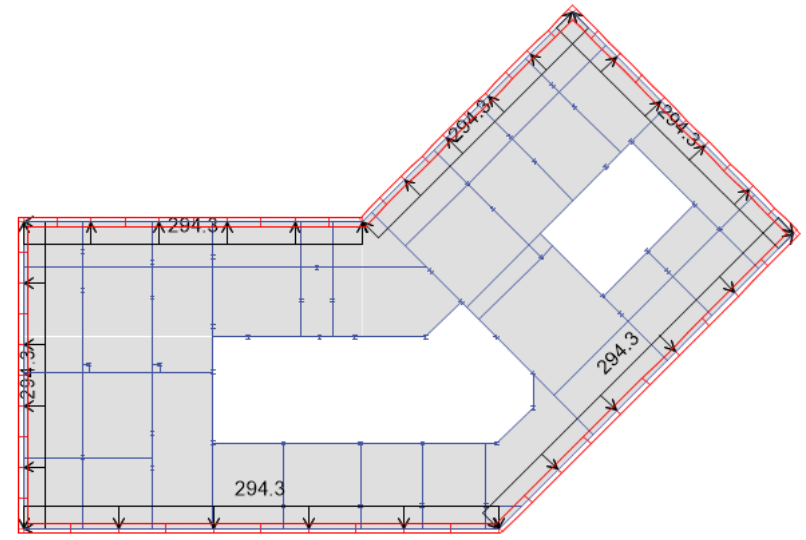

Figure.7 Ground pressure plane acting on the 1st floor in phase 2

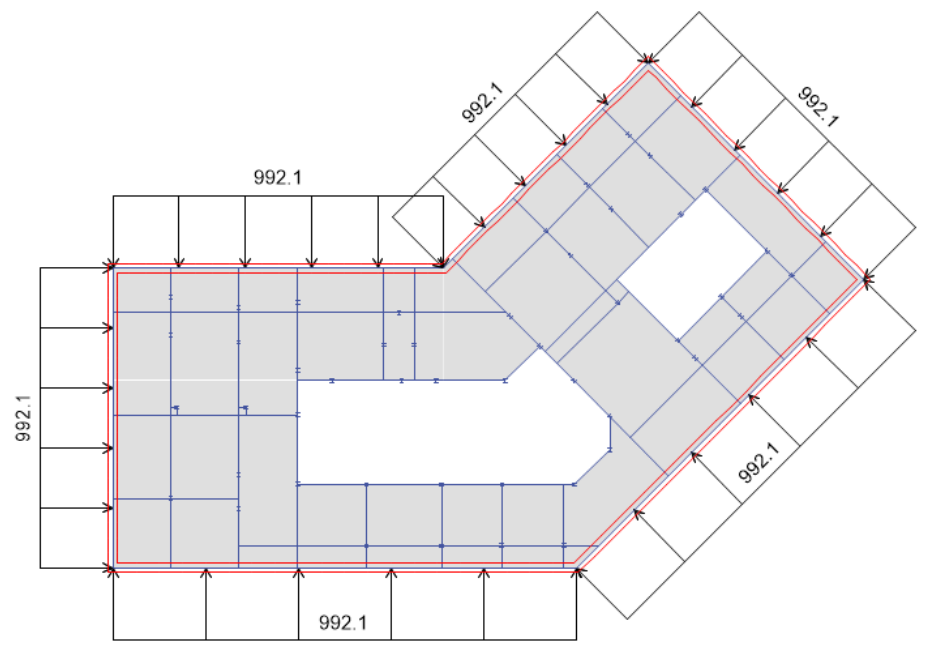

Figure.8 Ground pressure plane acting on basement B1 in phase 2

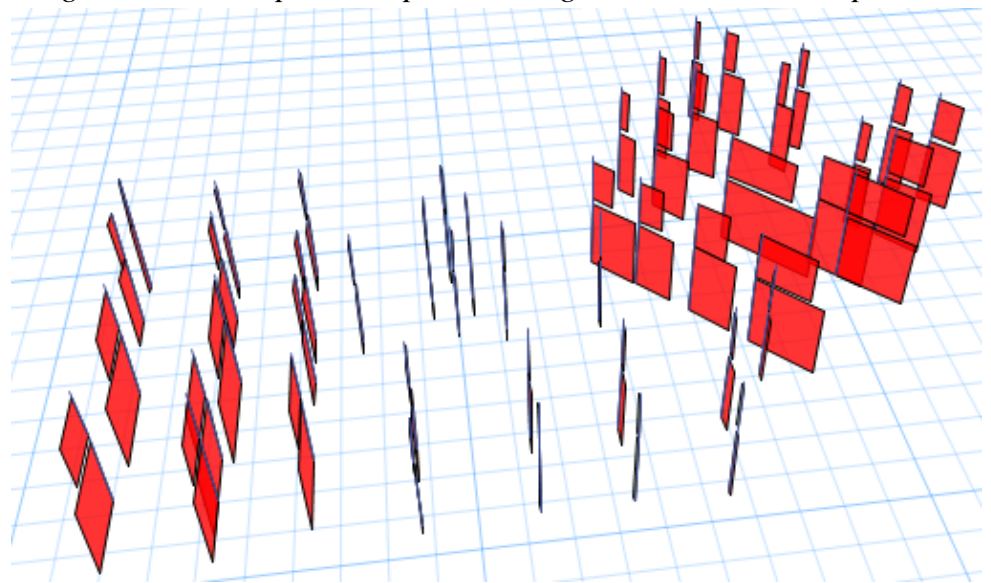

$\operatorname{Max}=180.637 \mathrm{kN}$ at $[34.3143 \mathrm{~m}, 2.2749 \mathrm{~m}, 0 \mathrm{~m}] ;$ Min $=-2021.7688 \mathrm{kN}$ at $[52.6831 \mathrm{~m}, 27.6413 \mathrm{~m}, 0 \mathrm{~m}]$ 
Fig. 9 Longitudinal force of kingpost system in period 2

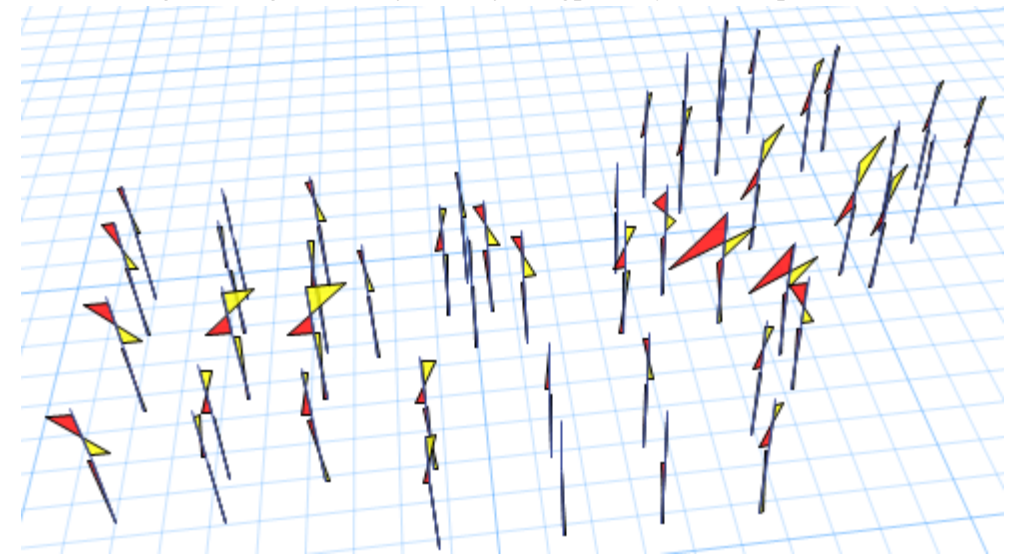

Max $=146.2862 \mathrm{kN}-\mathrm{m}$ at $[48.1324 \mathrm{~m}, 19.5041 \mathrm{~m}, 6.6 \mathrm{~m}] ;$ Min $=-242.8835 \mathrm{kN}-\mathrm{m}$ at $[48.1324 \mathrm{~m}, 19.5041 \mathrm{~m}, 6.6 \mathrm{~m}]$

Fig.10 Moment M22 of kingpost system in phase 2

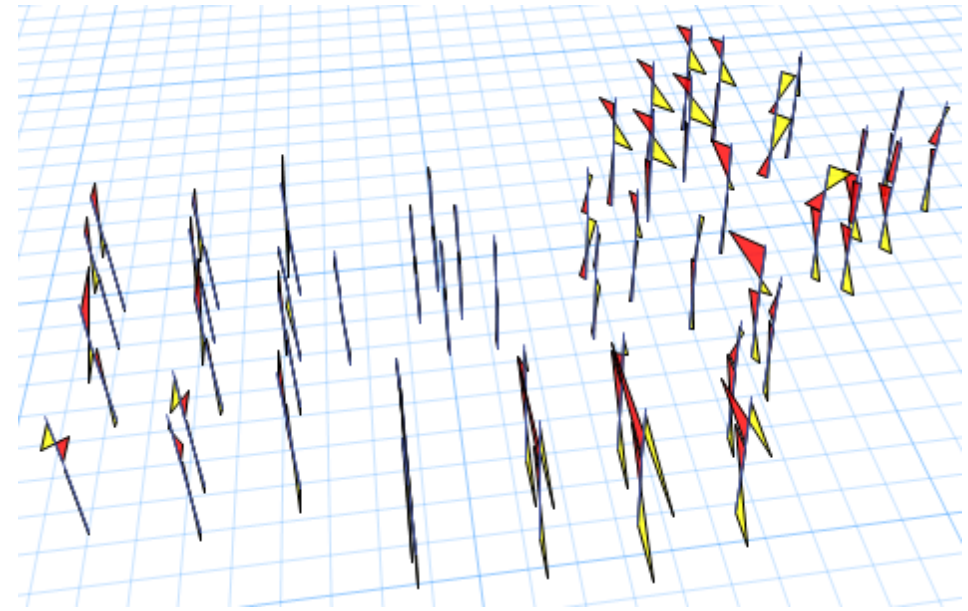

Max $=288.5405 \mathrm{kN}-\mathrm{m}$ at $[26.4376 \mathrm{~m}, 2.2736 \mathrm{~m}, 6.6 \mathrm{~m}]:$ Min $=-328.6341 \mathrm{kN}-\mathrm{m}$ at $[40.5976 \mathrm{~m}, 2.2749 \mathrm{~m}, 6.6 \mathrm{~m}]$

Fig.11 Moment M33 of kingpost system in phase 2

\section{CONCLUSION}

- The author analyzed the first phase of the construction process of the kingpost system

- The author has analyzed the second phase of the construction process of the kingpost system

- The development direction of the topic needs to do many optimization algorithms for more optimal results, saving more time and costs.

- In stage 1: Moment M22 Max is: $66.5909 \mathrm{KN}-\mathrm{m}$, Min is: -125.8434KN-m. Vertical force Max: 31.098KN-m, Min: -1501.2762KN-m, Moment M33 Max is: 67.5637KN-m, Min is: $-111.7043 \mathrm{KN}-\mathrm{m}$

- In stage 2: Moment M22 Max is: $146.2862 \mathrm{KN}-\mathrm{m}$, Min is: $-242.8835 \mathrm{KN}-\mathrm{m}$. Vertical force Max: 180,637KN-m, Min: $-2021,7688 \mathrm{KN}-\mathrm{m}$, Moment M33 Max is: $288,4105 \mathrm{KN}-\mathrm{m}$, Min is: $-328,6341 \mathrm{KN}-\mathrm{m}$

- Using the analyzed solution optimization algorithm is more economical and still ensures the bearing capacity of the system in phase 1 reduced by $15 \%$ during construction, phase 2 reduced by $17 \%$ during construction 


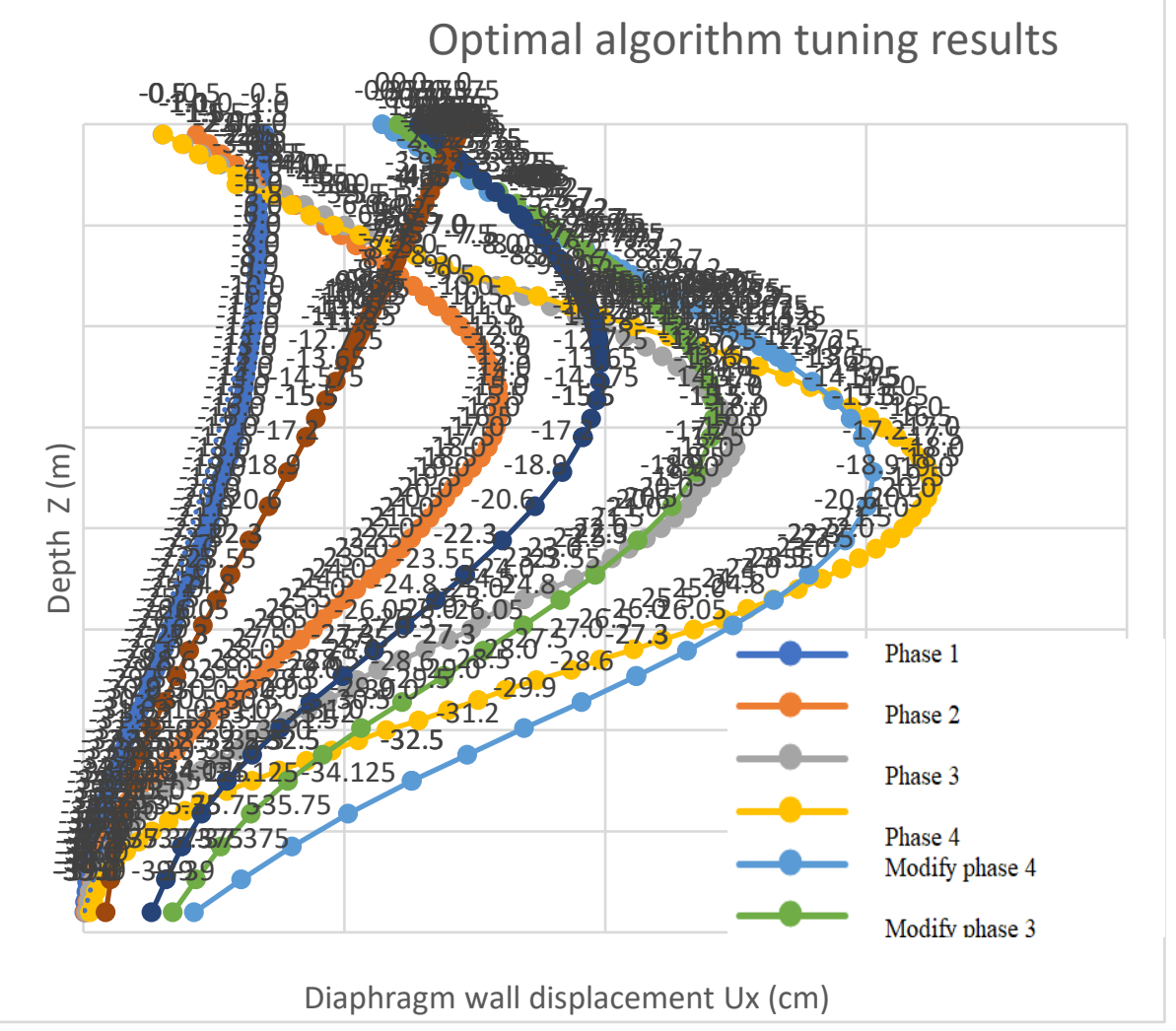

Figure .12 4-stage fin displacement

\section{ACKNOWLEDGEMENTS}

The author would like to thank the editors for reading through. Thank you for your feedback and suggestions for the author to develop better ideas.

\section{REFERENCES}

[1] Dung Tien Construction Company Ltd "Analysing and selecting construction method for Sacombank Buiding's basement report", 2010

[2] Bui Q T Graduate thesis "Analyze the behavior of diaphragm wall during excavation and construction of the basement floor” HoChiMinh city University of Technology. p71-108, 2011

[3] Ke Ng B "Design And Construction Of Deep Foundation Pit Construction Publisher".2002

[4] Lan Transport \& Authority "Bottom-Up \& Top-Down Construction Method", 2005.

[5] http://dungtien.com/en/project/done-project [6] Brinkgreve R B J, Vermeer P A 1998 PLAXIS 2D Foundation Version 7 Manual Balkema A A Rotterdam Brookfield Netherlands

[6] Huynh Van Hoang, Tran Thi Hong, Le Hong Son.” Steel structure of lifting equipment”. Ho Chi Minh City National University Publishing House.

[7] TCVN 4244:2005 - "Lifting equipment: Design, manufacture and technical inspection", Hanoi, 2006.

[8] Verschoof J. - Cranes -“ Design, Practice, and Maintenance, 2nd Ed., Professional Engineering Publishing Limited”, London and Bury St Edmunds, UK, 2002

[9] Kolarov I. "Metal structure of material handling machines", Technica, Sofia

[10] Trinh Dong Tinh, "Effect of calculated loads and structural parameters on the optimal size of the main girder of the two-girder box-type crane", scientific report on the occasion of 55 years of establishment of Hanoi University of Science and Technology. Interior, 2011

[11] Nguyen Hong Tien, 2013. "Optimal design of crane steel structure. Thesis of Master of Science in Engineering Mechanics", University of Science and Technology - Hanoi, 2013. 


\section{BIOGRAPHIES OF AUTHOR}

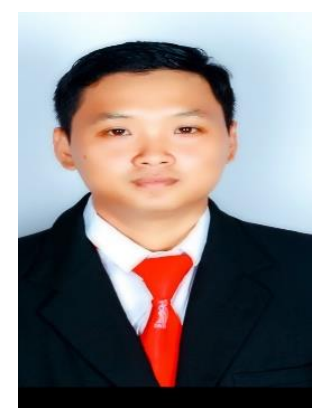

Bao- Nguyen Huu

Date of birth: November15, 1987

Phone: 0987584231

Email: nguyenhuubao@dntu.edu.vn

Address: Tiên Giang, Viet Nam 